\title{
O ESTADO DA ARTE DA PRODUÇÃO ACADÊMICA SOBRE O LETRAMENTO DIGITAL NA FORMAÇÃO DOCENTE
}

\section{EL TRABAJO ACADÉMICO DE VANGUARDIA EN LA ALFABETIZACIÓN DIGITAL EN LA FORMACIÓN DOCENTE}

\author{
THE STATE OF THE ART ACADEMIC WORK ON DIGITAL LITERACY IN \\ TEACHER EDUCATION
}

Patrícia Peixoto Carneiro VIEGAS ${ }^{1}$

Ilsa do Carmo Vieira GOULART ${ }^{2}$

RESUMO: Este texto resulta de uma pesquisa bibliográfica, analítica e descritiva, numa perspectiva metodológica do Estado do Conhecimento ou Estado da Arte, sobre letramento digital na formação de professores. Realizou um levantamento de teses e dissertações dos cursos de pós-graduação stricto sensu das Instituições de Ensino Superior do estado de Minas Gerais, no período de 2000 a junho de 2017, com o objetivo de identificar quais as tendências que as produções acadêmicas apresentam nas investigações sobre letramento digital na formação de professores. Como referencial teórico, aborda a cibercultura com Lévy (1999), o letramento, na perspectiva de Soares (1996, 2002, 2014) e Street (2014), os multiletramentos com Rojo (2003, 2012), letramento digital com Snyder (1999). Como resultado tem-se que as pesquisas são ainda incipientes ao tratar do tema e até mesmo superficiais, em alguns casos misturando o determinismo e o relativismo tecnológico. Verifica-se a diversidade nos constructos teóricos utilizados, que, por consequência, comprovam a heterogeneidade quando se trata de formação de professores.

PALAVRAS-CHAVE: Letramento digital. Formação de professores. Estado do conhecimento.

RESUMEN: Este texto es el resultado de una investigación bibliográfica, descriptiva y analítica, una perspectiva metodológica del estado de conocimiento o estado del arte, en la alfabetización digital en la formación docente. Llevó a cabo un estudio de tesis y tesis de postgrado en el sentido estricto de las instituciones de educación superior del estado de Minas Gerais, en el período de 2000 a junio de 2017, con el objetivo de identificar tendencias producciones académicas actualmente la investigación en alfabetización digital en la formación docente. Como marco teórico, habla de la cibercultura com Levy (1999), o Letramento, na perspectiva de Soares (1996, 2002, 2004), y Street (2014), multiletramentos con Rojo (2003, 2012), Alfabetización digital com Snyder (1999). Como resultado ha sido que la investigación es aún incipiente en el tratamiento del tema y superficial, incluso en algunos casos mezclando el determinismo y el relativismo. Hay una diversidad teórica que, en

${ }^{1}$ Centro Universitário Presidente Tancredo de Almeida Neves (UNIPTAN), São João del-Rei - MG - Brasil. Pesquisadora do Núcleo de Estudos em Linguagens, Leitura e Escrita. OrcID: http://orcid.org/0000-0002-13410098. E-mail: patypcr@hotmail.com

${ }^{2}$ Universidade Federal de Lavras (UFLA), Lavras - MG - Brasil. Departamento de Educação e Programa de Pós-Graduação em Educação. OrcID: http://orcid.org/0000-0002-9469-2962. E-mail: ilsa.goulart@ ded.ufla.br 
consecuencia, construye demostrando la diversidad cuando se trata de la formación del profesorado

PALABRAS CLAVE: Alfabetización digital. Formación de los docentes. Estado del conocimiento.

ABSTRACT: This text is the result of a bibliographical research, analytical and descriptive, a methodological perspective of the State of knowledge or State of the art, about digital literacy teacher training. Conducted a survey of theses and dissertations of postgraduate courses in the strict sense of the institutions of higher education of the State of Minas Gerais, in the period of 2000 to June 2017, aiming to identify which trends academic productions present the investigation on digital literacy in teacher training. As theoretical framework, discusses the Cyberculture with Lévy (1999), from the perspective of literacy Soares (1996, 2002, 2014), Street (2014) and Rojo 92003, 2012), digital literacy with Snyder (1999). As a result has been that the research is still incipient in treating of the theme and even surface, in some cases blending the determinism and relativism. There is a diversity in theoretical constructs that, consequently, show heterogeneity when it comes to teacher training.

KEYWORDS: Digital Literacy. Training of teachers. State of knowledge.

\section{Introdução}

O letramento é um fenômeno histórico e social, que, de certo modo, representa as atividades de leitura e de escrita de um determinado grupo e a forma como esse grupo se comunica e estabelece suas relações sociais. Diante de uma sociedade em que o escrito e o visual ganham visibilidade e autenticidade, as atividades de leitura e de escrita apresentam dimensões mais alargadas, em que novas práticas de uso se reconfiguram conforme as necessidades dos sujeitos e exigências da época.

Entendendo os letramentos como as práticas sociais cotidianas e as relações com a oralidade e a escrita, abordaremos um estudo a respeito do conceito de letramento perpassando por uma reflexão das ações influenciadas pelas tecnologias digitais nas práticas de ler e de escrever no contexto educacional, e que não devem ser confundidos com o letramento escolar.

Com o intuito de compreender quais são os resultados que têm sido alcançados nas pesquisas acadêmicas e científicas realizadas, em Minas Gerais, nos diversos segmentos educacionais; saber qual é o discurso que o professor faz e o que efetivamente tem sido feito na teoria e na prática; observar as contradições e o que ainda precisa ser estudado, desenvolve-se uma pesquisa documental direcionando-se, sobretudo, aos estudos de "Letramento Digital na Formação de Professores". 
Assim, esta pesquisa documental comprova que, no Brasil, os estudos sobre a temática letramento digital e formação de professores ainda são incipientes, e conforme apontaram as estatísticas mais adiante expostas, constatou-se que o tema só começou a ser frequentemente cotado a partir do ano de 2010. Em outros países já existiam estudos algumas décadas antes, como, por exemplo, os multiletramentos, no Grupo Nova Londres, em Connecticut, em 1996.

De modo simplificado, o Letramento Digital pode ser compreendido como o uso de práticas sociais de leitura e de escrita a partir de recursos digitais, conforme Soares (1996, 2002, 2014) e Buzato (2006), e será na escola o local do encontro de atitudes, de comportamentos e de habilidades diferentes das do século passado.

Nesta direção, vê-se a figura do professor como o responsável, não apenas pela função de ensinar, mas também de educar de forma crítica, cultural e instrumental para o uso dessas tecnologias digitais. Então, o que se tem pesquisado sobre a temática do letramento digital e formação de professores? Quais são as tendências nas pesquisas, em teses e dissertações, do estado de Minas Gerais, sobre o letramento digital na formação de professores?

Orientada por esses questionamentos, em busca de analisá-los e sintetizá-los, esta pesquisa tem como objetivo identificar quais tendências as produções acadêmicas apresentam nas investigações sobre letramento digital na formação de professores, no estado de Minas Gerais, no período de 2000 a junho de 2017, a partir de um levantamento de teses e dissertações dos cursos de pós-graduação stricto sensu das Instituições de Ensino Superior mineiras e de periódicos mineiros da CAPES (Coordenação de Aperfeiçoamento de Pessoal de Nível Superior) e publicações na ANPED (Associação Nacional de Pós-Graduação e Pesquisa em Educação).

Para tanto, delimitou-se esse espaço geográfico de Minas Gerais porque os letramentos, enquanto práticas sociais, devem ser entendidos nas suas particularidades. Dessa maneira, optou-se por centralizar o estudo nessa unidade federativa que é local em destaque na área da educação, por sua extensão e concentração de universidades e instituições de ensino variadas. Não obstante, em âmbito nacional também estão sendo feitas diferentes pesquisas sobre o letramento digital, nas diversas áreas do conhecimento, o que permitirá, posteriormente, uma comparação com trabalhos que já realizaram o Estado da Arte sobre o tema.

As buscas iniciais realizadas na presente pesquisa foram na produção de trabalhos acadêmicos, na área do letramento digital, que se deu pela leitura dos títulos e resumos dos trabalhos, que apontavam ou traziam, em suas discussões, a temática da formação docente. 
Como recorte temporal, foram selecionadas as produções acadêmicas a partir do ano 2000 até 2017, já que o período inicial marca a virada do milênio e do século, momento em que muitas evoluções cibernéticas adentraram no cenário brasileiro e também nas instituições sociais, com a banda larga, as interfaces, o World Wide Web (www), as redes sociais, entre outros. E o marco final será o ano de 2017, até o momento de escrita da pesquisa.

Ao considerar uma abordagem quantitativa e qualitativa foi utilizada a metodologia descritiva, exploratória e bibliográfica pelo "Estado da Arte" ou "estado do conhecimento", que, segundo Ferreira (2002), pode ser compreendida como a investigação do conjunto de trabalhos acadêmicos, à luz de categorias e facetas, sob os quais o fenômeno será analisado. A análise qualitativa de cunho analítico e interpretativo será realizada pela metodologia da Teoria Fundamentada em Dados por Glaser e Strauss (1999).

Dotam-se, na abordagem quantitativa, a quantificação e a identificação de dados bibliográficos, a fim de mapear as produções, a partir do recorte temporal, espacial e áreas de produção. E, na abordagem qualitativa, procura-se observar e tabular dados, para levantar as tendências escolhidas, analisando seus objetivos, metodologias e resultados, ou seja, "o quê" se discute sobre o letramento, observando a base temática dos trabalhos e "o como" são desenvolvidas as pesquisas a respeito do letramento digital na formação de professores, observando suas bases metodológicas (FERREIRA, 2002).

Para se adentrar o fenômeno do letramento digital, serão trazidos conceitos sobre o letramento e algumas de suas discussões e de suas particularidades, como os modelos autônomos e ideológicos dos novos letramentos por Street (2014), as semelhanças e as diferenças das habilidades cognitivas de uma sociedade oral e de uma sociedade escrita por Oslon (1995), Soares (1996, 2002, 2014) e Kleiman (2014), por se entender o letramento digital como uma das possibilidades desse fenômeno social e que, também, está relacionado à classificação de multiletramentos de Rojo (2003, 2012).

\section{Oralidade e escrita nos novos letramentos}

$\mathrm{Na}$ configuração do fenômeno dos "novos letramentos", existe a influência de circunstâncias e habilidades individuais e sociais, mas que abrangem inúmeras situações. Para Barton e Hamilton (2012, p. 13), “[...] um primeiro passo na reconceitualização do letramento é aceitar as múltiplas funções que o letramento pode servir em uma determinada atividade, onde pode substituir o idioma falado, tornar possível a comunicação, resolver um problema prático ou agir como um auxílio à memória - em alguns casos, todos ao mesmo tempo". 
Alguns grupos fazem uso da oralidade para resgatar tradições e/ou realizar tarefas diárias, enquanto outros recorrem à escrita para concretizar os mesmos atos. Independente da opção, a interação e a prática social alteram e substituem alguns hábitos de acordo com as influências que sofrem da política, da economia e das demais culturas.

O letramento acaba surgindo de diferentes maneiras nas variadas regiões e culturas. Não que se pretenda substituir uma cultura por outra mais globalizada. Pode ser que essa comunicação global, com diferentes práticas orais e escritas, fortaleça a cultura ou a influencie de outras maneiras. Mas, vale lembrar que o objetivo principal dessas práticas sociais é a solução de conflitos para as interações no dia a dia.

Mesmo assim, ainda, na contemporaneidade, há uma dicotomia entre as sociedades letradas e orais, bem como uma visão pejorativa dessa segunda pelos letrados. No estudo dos "novos letramentos", proposto por Street (2014) e outros estudiosos, pode-se perceber que aquela assertiva, de superioridade da escrita sobre a oral, deve ser desmistificada, já que não há que se falar em uma sociedade mais bem preparada do que a outra e, além disso, existem contribuições de ambas as modalidades.

Apesar de em algumas culturas o letramento e a transição da cultura oral para a escrita, como assinala Street (2014), sejam compreendidos como sua associação ao progresso, não se pode afirmar que um desses usos tem mais valor que o outro, ou que é mais complexo, ou que seja sinônimo de evolução. Essa diferenciação, instintivamente, pode levar à reprodução de preconceitos com denominação de quem sabe ler e dos que não sabem (KLEIMAN, 2014).

Em relação à oralidade e à escrita, suas distinções e semelhanças tiveram grande impulso com os primeiros autores que estudaram, conforme atribui Olson (1995), a "teoria da escrita". Isto é, Havelock, Ong, MacLuhan, Goody e Watt e outros estudiosos, de diferentes áreas, trouxeram contribuições científicas para esses fenômenos ao pesquisarem a escrita alfabética. Em um segundo momento, outros pesquisadores complementaram, diminuindo a dissociação que havia se formado entre a oralidade e a escrita.

Olson (1995) apresenta que numa primeira fase foi usado o argumento da escrita como sendo o ato de escrever o responsável pela evolução dos novos discursos, uma nova compreensão da linguagem e de mente (mais subjetiva, abstrata e reflexiva) e capaz de novas formas de organização social. Esse pensamento inferiorizava a oralidade. Mais tarde foi superado por alguns pesquisadores, como Scribner e Cole (1981), já na segunda fase de autores, argumentaram que foi o processo de escolarização que permitiu essas mudanças, e não a escrita em si. Logo, infere-se que as diferentes formas de linguagem fazem parte desse 
processo de evolução, não havendo uma mais significante que a outra, e que vão ter diferentes valores de cultura para cultura.

Os textos orais podem colaborar para uma memorização, para uma forma de recepção e preservação da memória; a escrita, por sua vez, trouxe diferentes funções e gêneros textuais, condição de destinatário dos textos e mudanças nos processos cognitivos e discursivos (SOARES, 2002).

Nesse viés frisa-se que o letramento não deve ser estudado dissociado da oralidade, já que a prática social vai depender não só da leitura e da escrita, mas também do contexto em que está inserida. Assim, deve-se compreender que o letramento ocorre em diferentes instâncias sociais e que se vive num momento de grandes mudanças decorrentes do uso das tecnologias de informação e de comunicação, ocasionando diferentes linguagens em meios multimidiáticos, as multimodalidades, além do desenvolvimento de novas habilidades cognitivas.

Para Kleiman (2014), as Tecnologias de Informação e de Comunicação sofrem influências das diversas culturas e, em face de todo o exposto, é necessário considerar o tratamento da linguagem oral e escrita indissociavelmente para dar continuidade ao entendimento do processo de desenvolvimento linguístico, e não que haja uma ruptura, como vem ocorrendo na práxis escolar.

A criança ou o indivíduo que mesmo vivendo em uma sociedade letrada, quando ainda não sabe ler e escrever, se comunica e tem resultados pela oralidade. Partindo desse pressuposto, a escola, segundo Kleiman (2014), tem a missão de dar continuidade ao letramento dos seus alunos, com a aquisição da leitura e da escrita também pelas vivências orais daquele grupo, naquele contexto, ou seja, privilegiando o conhecimento individual e coletivo que são apresentados no ambiente escolar.

Sem esquecer que, hoje, os estudantes que chegam aos bancos escolares, supostos "nativos digitais" (PRENSKY, 2001), isto é, crianças, adolescente e adultos munidos de aparatos digitais no dia a dia e fazem uso de recursos tecnológicos para lazer, para estabelecer comunicações e até para aprofundar o processo de aprendizagem.

Em consonância com as autoras Soares (2014) e Kleiman (2014), Street (2014) criticou, em uma de suas obras, a dicotomia entre a fala e a escrita e a concepção dominante do letramento, reduzindo-o a um conjunto de capacidades cognitivas, o que veio a ser denominado por ele como "modelo autônomo", predominante nas atividades da UNESCO. Por outro lado, denominou como "modelo ideológico" o letramento em suas práticas sociais e concretas. Através de sua pesquisa etnográfica, Street (2014) pôde perceber a tendência mais 
ampla do letramento como uma prática social e numa perspectiva transcultural. Dessa maneira, defende o autor a aplicação do modelo ideológico de letramento.

Discorrendo sobre os modelos de letramento, Street (2014) sugere que os programas nacionais e internacionais para letramento, propostos nos anos de 1990, têm traços do modelo autônomo, tendo em vista as estratégias que propunham ao indivíduo aprender a ler e a escrever seguindo algumas metodologias, mas que, depois de transcorrido o prazo estipulado, não se tinha êxito. Soares (2014) afirma que tais programas não dão condições para as crianças e adultos se alfabetizarem, já que não disponibilizam materiais e acesso à leitura e à escrita que são necessários para dar continuidade ao processo de letramento.

Além disso, o que acontece é que tais campanhas de alfabetização têm menosprezado os letramentos locais e os indivíduos com dificuldade de leitura e escrita, que já passam a ser classificados como analfabetos. Em consonância com este assunto, pode ser citado, aqui, Freire (2015, p. 79), que defende a leitura como algo mais abrangente do que a leitura do código linguístico, visto que a "[...] leitura de mundo, que precede sempre a leitura da palavra”. Isto é, o indivíduo deve ser compreendido a partir do meio em que ele vive, das suas experiências socialmente construídas e, daí, serem propostas metodologias de ensino e não o contrário. Assim, também, com as tecnologias. Devem ser usadas além da sua instrumentalidade ou da sua imposição por órgãos hierarquicamente superiores. Talvez diante da prática cotidiana de cada participante dessa relação, o professor, ao estar preparado, consiga criar meios para o uso crítico e cultural desses recursos.

Os novos letramentos trazem a discussão da oralidade e da escrita, que devem ser indissociáveis no momento do desenvolvimento linguístico. No entanto, não é o que ocorre com as propostas da UNESCO, como já mencionado, em que há uma diferenciação entre oralidade e escrita, prevalece um modelo autônomo de letramento, segundo Street (2014). Apesar disso, a escrita não deve ser reconhecida como superior. Como foi posto, o que apresenta mudança é o processo de escolarização. Neste interim, preocupa-se com a possibilidade de uma participação e uma postura em que o aluno consiga utilizar a linguagem para solucionar seus conflitos socais, seja com a oralidade, seja com a escrita ou seja com as tecnologias digitais. A preocupação é entender como a oralidade e a escrita podem ser exploradas e benéficas na escolarização do indivíduo através das tecnologias digitais, a ser preconizado o modelo ideológico de letramento. Tais considerações interferem diretamente no processo de formação docente. 


\section{Letramento digital: em busca de compreensão conceitual}

As grandes mudanças nas formas de comunicação e de interação entre os sujeitos, entre o sujeito e o conhecimento, entre o sujeito consigo mesmo, proporcionadas pelas tecnologias digitais de informação e comunicação, em ampla expansão a partir da década de 1980, trazem uma nova configuração na dinâmica das relações sociais com a informação e com o conhecimento, em que as formas de letramentos se distinguem.

Para uma melhor compreensão deste fenômeno social das tecnologias, Lévy (1999) traz o conceito de ciberespaço, no final do século passado, classificando-o como uma rede de comunicação entre pessoas, coisas e ideias, que se limita ao código digital e permite o suporte da memória, da comunicação e da informação a partir do seu caráter "plástico, fluido, calculável com precisão e tratável em tempo real, hipertextual, interativo e, resumindo, virtual” (LÉVY, 1999, p. 95).

A benesse do ciberespaço, de controlar ou de acompanhar o desenvolvimento de tecnologias e informações, ocorre pela inteligência coletiva. Conceito de Lévy (1999) para designar a inteligência como um dos propagadores de informações cada vez mais personalizadas e efetivas a partir "de uma sinergia entre competências, recursos e projetos, a constituição e manutenção dinâmicas de memórias em comum, a ativação de modos de cooperação flexíveis e transversais, a distribuição coordenada dos centros de decisão" (LÉVY, 1999, p. 29).

A ferramenta da inteligência coletiva pode ser visualizada em diversos meios, como, por exemplo, no espaço profissional ou em âmbito educacional. Na educação, os cursos de modalidade a distância são desenvolvidos como sistemas de aprendizagem cooperativa, isto é, os alunos, os tutores e os professores trocam textos, experiências e ideias de acordo com o interesse específico. A partir daí quem sabe mais em uma área auxilia o outro e a sua recíproca pode ser verdadeira. Logo, existe uma descentralização do poder alimentador da rede (LÉVY, 1999).

Há a possibilidade de, cooperativamente, concentrar os esforços para a produção de um ambiente virtual acessível e dinâmico, em que os interessados possam opinar e modificar esse espaço, de modo que as operações se tornem mais atrativas, relevantes, personalizadas e atinjam o objetivo da comunicação.

Além da inteligência coletiva, outros elementos caracterizam a ascensão do ciberespaço, a saber, a interconexão e a criação das comunidades virtuais. A interconexão, para Lévy (1999), trata-se da possibilidade de comunicação sem fronteiras, enquanto as 
comunidades virtuais são a reunião de pessoas, de interesses, ou até mesmo troca de informações e experiências, ou seja, interações diversas.

O uso de múltiplos recursos digitais e de forma cada vez mais particularizada permite que as funções antes exercidas pelo indivíduo, ao memorizar ou ao registrar no papel, sejam modificadas, além de serem precisas e flexíveis. Nesse sentido, as novas interações exigem do indivíduo o desenvolvimento de outras habilidades cognitivas, enquanto algumas outras serão abandonadas.

Além de apresentarem uma diversidade e uma facilidade de acesso às suas interfaces estéticas que permitem o compartilhamento de informações e de ideias, com um grande número de pessoas, em um curto espaço de tempo, de múltiplas formas, com o uso de variadas habilidades. Essas mudanças no acesso à informação podem tanto ser consideradas vantagens como desvantagens. A desvantagem ocorre, conforme assinala Lévy (1999), nos momentos de isolamento e de sobrecarga cognitiva, de dependência, de dominação, de exploração etc.

A reprodução de ideologias ocorre como um vírus pelas redes sociais e pelas mídias em geral, o que pode influenciar nas exclusões sociais ou, ainda, pode oportunizar o conhecimento de culturas minoritárias, ou terminar por eliminá-las.

Surgem, também, novas formas de uso social do ler e do escrever a partir dos recursos digitais. As práticas, as atitudes, as técnicas usadas por meios digitais de uma instituição social caracterizam-se como cibercultura (LÉVY, 1999). Esses artifícios usados na sociedade para estabelecerem uma comunicação em rede influenciam diretamente no comportamento dos indivíduos no presente século.

Assim, a sociedade do Século XXI é denominada por Castells (2005) como uma sociedade em redes, em que as relações sociais organizam-se a partir das novas tecnologias, ou seja, as transações entre pessoas, coisas e ideias se fazem pelo uso de informações e de conhecimentos pelo meio mediático.

Ultrapassa-se a visão da sociedade do conhecimento ou da informação, pelo modo como ela passa a se estruturar. E, apesar de estarem presentes tanto a diversidade global quanto a exclusão social digital, as tecnologias, as suas multimodalidades de comunicação e os novos comportamentos dos indivíduos em comunidade e as suas habilidades precisam ser entendidos, no espaço em que ocupam, seja real ou virtual, com suas peculiaridades e características.

Desse modo, Porto (2006, p. 44) compreende como tecnologias "os produtos das relações estabelecidas entre sujeitos com as ferramentas tecnológicas que têm como resultado 
a produção e a disseminação de informações e conhecimentos". Foca, ainda, sobre o seu uso, no ambiente escolar, que é o espaço de socialização, de saberes e conhecimento científico (PORTO, 2006). Nesse sentido, as tecnologias na educação têm uma relação com as práticas sociais de cada grupo, que vão possibilitar maior ou menor acesso ao conhecimento, ou como o livro didático, ou mesmo como um aparato digital.

Assim sendo, as habilidades cognitivas desenvolvidas através dessas tecnologias digitais, principalmente por crianças e por jovens, do presente século, ou seja, os denominados nativos digitais por Prensky (2001), abrangem mais habilidades do que aquelas apenas observadas e desenvolvidas somente nas escolas.

Porto (2006) cita algumas potencialidades do uso de tecnologias de informações e comunicação na escola, entre elas destacam-se: a rapidez, a individualização, a interatividade, a hipertextualidade, a realidade virtual, a ideologia, etc.

Diante desse diapasão, vê-se a necessidade de preparação do grupo docente para o uso desses recursos na escola de forma crítica e funcional, pois, para Prensky (2001, p. 2), os professores são tidos como imigrantes digitais "que usam uma linguagem ultrapassada de era pré-digital e estão lutando para ensinar jovens que falam uma linguagem totalmente nova". Apesar das mudanças que a cada ano ocorrerem de forma evolutiva, ainda se verifica que alguns professores permanecem na era da imprensa.

As linguagens, as conexões e as interações que os professores utilizam costumam ser desconexas da realidade dos estudantes que não se prendem à rigidez dos sistemas, dos planejamentos, dos objetivos, dos currículos.

Lévy (1999) aponta que a cibercultura possibilita fazer uso das multimodalidades para se atingir o conhecimento. Assim acontece nas diversas instituições sociais, como a escola, o grupo familiar ou o grupo religioso. Ao saber que antes era transmitido, nas sociedades escritas, por uma composição estática e com mensagens universais bem contextualizadas e autossuficientes, agora se adiciona técnicas que se assemelham às características cognitivas de uma sociedade oral, com novas interações multilineares e multissequenciais, onde ocorrem diferentes interações entre o ser humano e o conhecimento (SOARES, 2002). E o professor precisa estar alerta.

O professor será um mediador do processo de ensino e de aprendizagem, ou seja, um elemento essencial para que o letramento digital do indivíduo ocorra, já que o letramento digital pode ser entendido, então, como as ações de compreensão e de práticas na esfera do mundo digital (DUDENEY; HOCKLY; PEGRUM, 2016). 
E para que ambos, professor e aluno, sejam considerados letrados digitalmente devem atender o modelo 3D, de Snyder (1999), que são as dimensões: operacional (saber utilizar a tecnologia digital); cultural (que as práticas sociais sejam de pertencimento e de eficácia no grupo ao qual faz parte); e, por fim, crítica (ao ter conhecimento da ferramenta tecnológica e do seu conteúdo, poder questioná-las e transformá-las, se necessário).

Os letrados digitais, ainda para Dudeney, Hockly e Pegrum (2016), tem a capacidade de se comunicar via SMS, utilizar diferente recursos visuais e auditivos, ao fazer um hipertexto, através de jogos, ao fazer uso da linguagem de computação, em pesquisas, ao construir uma rede, inclusive na projeção de uma identidade online, na comunicação com diferentes pessoas, de diferentes culturas e em novas práticas na rede digital. O que abre espaços para uma discussão sobre o processo de formação docente em relação aos usos de recursos tecnológicos no processo de ensino e aprendizagem e das vivências de um modelo de letramento ideológico na educação.

\section{Letramento digital na formação docente}

O futuro, em que as tecnologias seriam parte da educação, já se faz presente. Nóvoa (2009) faz uma menção à escola do século XXI, em que as tecnologias estariam inseridas no processo de aprendizagem e que o ensino seria individualizado, abandonando antigas práticas do ensino tradicional, podendo a educação ocorrer a qualquer hora do dia ou dia da semana, existindo a presença de professores reais e virtuais.

Essas mesclas entre espaços físicos e virtuais estão sendo recorrentes. A aprendizagem híbrida está sendo inserida nas escolas e nas universidades; será que os professores estão preparados para abandonar antigos hábitos e começar com uma nova perspectiva de prática educativas que as tecnologias digitais permitem? Como o processo de formação inicial e continuada tem abordado a questão referente ao processo educativo com base nas tecnologias digitais? Será que existem regras ou procedimentos em que o grupo de professores sejam letrados digitalmente? O que as produções acadêmicas trazem em seus estudos a respeito do letramento digital na formação docente?

Iniciando a caracterização de um docente letrado, coloca-se em evidência, sob uma perspectiva sociocultural, um professor habilidoso, aquele que ao mesmo tempo consegue ensinar seus conteúdos, consegue fazer uma abordagem de letramento como prática social crítica (STREET, 2014); se utilizando, ainda, de recursos digitais para fazer críticas ao letramento que se apropriam e reproduzem as relações de poder. 
Então, não só preocupado com o domínio do conteúdo, o professor ao se utilizar da linguagem, inclusive a linguagem de programação (usada nas tecnologias digitais), deve promover situações para um letramento crítico, que é a capacidade de opinar, levantar perguntas e redesenhar as escolhas. O letramento crítico deve ser estimulado em qualquer aprendizagem, inclusive ao se tratar de letramento digital.

Outra expectativa de um docente letrado digitalmente é o desenvolvimento profissional. O professor deve querer e buscar formas para aprimorar o conhecimento, através de um curso, de um projeto; além disso, são as ações colaborativas que contribuem para uma aprendizagem efetiva (DUDENEY; HOCKLY; PEGRUM, 2016).

Pode ser que a troca ocorra entre os próprios professores ou que seja por meio de um aluno que tenha uma habilidade maior com as tecnologias. Nesses casos, existe o medo de que o professor seja dominado por seu aluno, mas existem algumas situações, caso o professor opte pela ajuda de um aluno, não precisa se expor diante de uma turma, deve haver o momento de exploração dos recursos. Além disso, o diálogo será a solução para a maioria dos temores que existem.

Vale frisar que o objetivo do professor deve ser se tornar ativo e não apenas receptor daquela informação ou conhecimento, assim como o desejo de tirar o seu aluno da passividade. Nas atividades colaborativas existem estratégias que podem ser adotadas para que se tenha um resultado satisfatório; para Dudeney, Hockly e Pegrum (2016), essas respostas acontecerão através da autoavaliação, avaliação por pares, avaliação (somativa ou formativa) e o feedback ao professor.

Nesta perspectiva, emerge-se a necessidade de se identificar intencionalidades e as possibilidades de troca de experiência entre os pares sobre o uso de tecnologias digitais pelos professores em sala de aula, com o intuito de compreender tendências e quais resultados têm sido alcançados nas pesquisas acadêmicas e científicas realizadas, especificamente, em Minas Gerais.

\section{Produção Acadêmica sobre letramento digital na formação docente}

Trata-se de uma pesquisa que tem uma abordagem quantitativa e qualitativa, com objetivo de fazer o levantamento de algumas informações a partir de produções acadêmicas de teses e dissertações para se analisar o fenômeno do letramento digital na formação de professores descritas em pesquisas. Para a realização da presente pesquisa, foi determinado o período de 2000 a 2017 (até junho), um recorte temporal e um recorte local, delimitando a 
investigação das produções científicas apenas no estado de Minas Gerais, levando em conta a extensão e número populacional do estado, por sua importância econômica, política e social.

Para o levantamento de dados das pesquisas encontradas optamos pela leitura e análise dos resumos de cada produção científica, a fim de "selecionar e organizar o material divulgado" (FERREIRA, 2002, p. 263).

Segundo Garrido apud Ferreira (2002), os resumos passaram a ser um instrumento indispensável da literatura científica, já que têm caráter informativo e facilitam a divulgação e acesso aos estudos. Logo, pelo objetivo geral de investigação, pela "a metodologia/procedimento utilizado na abordagem do problema proposto; o instrumento teórico, técnicas, sujeitos e método de tratamento dos dados; os resultados; as conclusões e, por vezes, as recomendações finais" (FERREIRA, 2002, p. 202), nortearam o processo de análise.

Com base nesta perspectiva, categorizou-se a produção acadêmica a respeito da formação de professores e o letramento digital. Com leitura e análise dos resumos como corpus da pesquisa, pretendeu-se compreender o que esta produção acadêmica prioriza ou enfatiza sobre a temática a partir de diferentes perspectivas de seus pesquisadores. Observouse o direcionamento argumentativo que trazem sobre um mesmo objeto em seus fragmentos, o que permitiu uma expansão do conhecimento construído sobre um mesmo tema de pesquisa, em diferentes momentos ou não.

Para a compilação de dados para a pesquisa houve uma dedicação inicial de busca de produções científicas nos programas de pós-graduação sobre letramento digital na formação de professores. Para tal feito, realizou-se um levantamento das produções acadêmicas, na Plataforma Sucupira sobre quais eram os Programas de Pós-Graduação stricto sensu "Recomendados e Reconhecidos" no estado de Minas Gerais.

A partir deste levantamento obteve-se o total, na data da realização da pesquisa: em 04/11/2016, de 431 programas de pós-graduação e 641 cursos de pós-graduação. Em junho de 2017, na tentativa de buscar novos e atuais trabalhos, foi feita a mesma busca. Vale lembrar que houve um aumento de número de programas de pós-graduação para 448 e 660 a quantidade de pós-graduação, em 50 diferentes instituições de ensino.

Em julho de 2017 foi definido o prazo final para as buscas de teses e dissertações, tendo em vista a iniciação da análise dos dados e escrita do presente trabalho, assim, foi feita uma pesquisa nos sites do "Instituto Brasileiro de Informação em Ciência e Tecnologia ibict", em seu banco de dados de teses e dissertações e na plataforma Capes sobre as produções acadêmicas na área de letramento digital e formação docente. 
Ante o exposto, alcançou-se 16 (dezesseis) Instituições de Ensino Superior do estado de Minas Gerais que trataram desses assuntos: "formação de professores" e "letramento digital", sendo um total de 62 (sessenta e dois) trabalhos que trataram de alguma forma desses temas.

Tabela 1 - Pesquisas e instituições, segunda análise.

\begin{tabular}{|c|c|c|c|c|}
\hline Número & $\begin{array}{c}\text { Instituição de } \\
\text { Ensino Superior }\end{array}$ & $\begin{array}{c}\text { Teses e/ou Dissertações sobre } \\
\text { "formação de professores" e } \\
\text { "letramento digital" }\end{array}$ & $\begin{array}{c}\text { Número de } \\
\text { Cursos de Pós- } \\
\text { Graduação }\end{array}$ & $\begin{array}{c}\text { Número de } \\
\text { Programas } \\
\text { de Pós- } \\
\text { Graduação }\end{array}$ \\
\hline 1 & FUMEC & 1 & 7 & 8 \\
\hline 2 & PUC & 7 & 30 & 18 \\
\hline 3 & UFJF & 7 & 54 & 36 \\
\hline 4 & UFLA & 4 & 53 & 31 \\
\hline 5 & UFMG & 8 & 151 & 83 \\
\hline \hline 6 & UFOP & 2 & 64 & 28 \\
\hline 7 & UFU & 5 & 15 & 11 \\
\hline 8 & UFTM & 2 & 5 & 3 \\
\hline 9 & UNIVAS & 1 & 2 & 2 \\
\hline 10 & UMA & 2 & 21 & 17 \\
\hline 11 & UNIFEI & 2 & 6 & 5 \\
\hline 12 & UNIUBE & 1 & 10 & 7 \\
\hline 13 & CEFET & 43 & 572 & 373 \\
\hline
\end{tabular}

Fonte: Viegas (2018)

Apesar de na primeira análise serem encontrados trabalhos a partir dos filtros disponibilizados, houve a necessidade de generalização do termo "letramento digital" para "letramento", o que possibilitou um maior alcance de pesquisas, ao mesmo tempo em que trouxe trabalhos que não estavam dentro da temática e que foram excluídos pelos motivos da falta de relação com as duas temáticas simultâneas de "letramento digital" e "formação de professores" ou por não tratarem de pesquisa realizada dentro do estado de Minas Gerais.

Neste sentido, as instituições de ensino superior que apresentaram um número maior de trabalhos, na temática do letramento digital e formação de professores, foram a Universidade Federal de Minas Gerais (UFMG), a Pontifícia Universidade Católica (PUC), a Universidade Federal de Juiz de Fora (UFJF) e a Universidade Federal de Uberlândia (UFU).

A UFMG (Universidade Federal de Minas Gerais), localizada na capital do estado de Minas Gerais, é uma das instituições de ensino superior que apresentou o maior número de programas pós-graduação strito sensu, com 83 (oitenta e três), nas diversas áreas, sendo três os que trataram sobre a temática, são eles: Educação e Docência, Estudos Linguísticos e Educação, sendo contempladas, respectivamente, as seguintes áreas de conhecimento: Educação Tecnológica e Sociedade, Linguística Aplicada e Educação e Linguagem, 
totalizando 8 (oito) trabalhos encontrados, ou seja, 17\% (dezessete por cento) dos 43 (quarenta e três) pesquisados.

Já a PUC (Pontifícia Universidade Católica), também localizada na capital, com os seus dezoito (18) programas, sete (7) puderam ser considerados pelas pesquisas, com $15 \%$ (quinze por cento) dos trabalhos, sendo os programas de Educação e de Letras, que estudam as seguintes áreas do conhecimento: Linguística, Linguística e Língua Portuguesa, Sociologia, História da Profissão Docente e Educação Escolar. Interessante ressaltar que houve uma pesquisadora que desenvolveu tanto na sua dissertação de mestrado, quanto na sua tese de doutorado temas afins, o que permite concluir a continuidade da pesquisa sobre o tema.

Por sua vez, a UFJF (Universidade Federal de Juiz de Fora) também apresentou 7 (sete) trabalhos, portanto, 15\% (quinze por cento). Estes trabalhos foram desenvolvidos em pós-graduações em Gestão e Avaliação da Educação Pública, em Educação, em Letras e em Linguística, dentre os trinta e seis (36) programas de pós-graduação que a universidade apresentou.

A UFU (Universidade Federal de Uberlândia) obteve um destaque com 5 (cinco) trabalhos e $11 \%$ (onze por cento). A referida universidade tem 44 (quarenta e quatro) programas de pós-graduação, cujas áreas contempladas nos trabalhos científicos selecionados foram Linguística, Geografia e Gestão do Território, Educação de Ciências e Matemática e Educação.

Os referenciais teóricos usados foram diversificados. No entanto, nem todos os resumos apresentaram seus referenciais teóricos.

Os autores que mais se repetiram foram Bakhtin, Vygostky, Wenger, Rojo, Soares, Lévy, Freire e Buzato.

O letramento digital, em sentido amplo, está intimamente ligado à inclusão social, assim como ao processo de ensino-aprendizagem e à formação de professores. Isto porque o letramento digital como categoria central se divide em subcategorias, a saber: (a) tecnologização digital, (b) agente formador, (c) ensino-ação digital e (d) acesso digital.

A Figura 1 apresenta como essas subcategorias estão associadas entre si e dentro do âmbito de instituições de formação de professores. 
Figura 1 - Subcategorias associadas

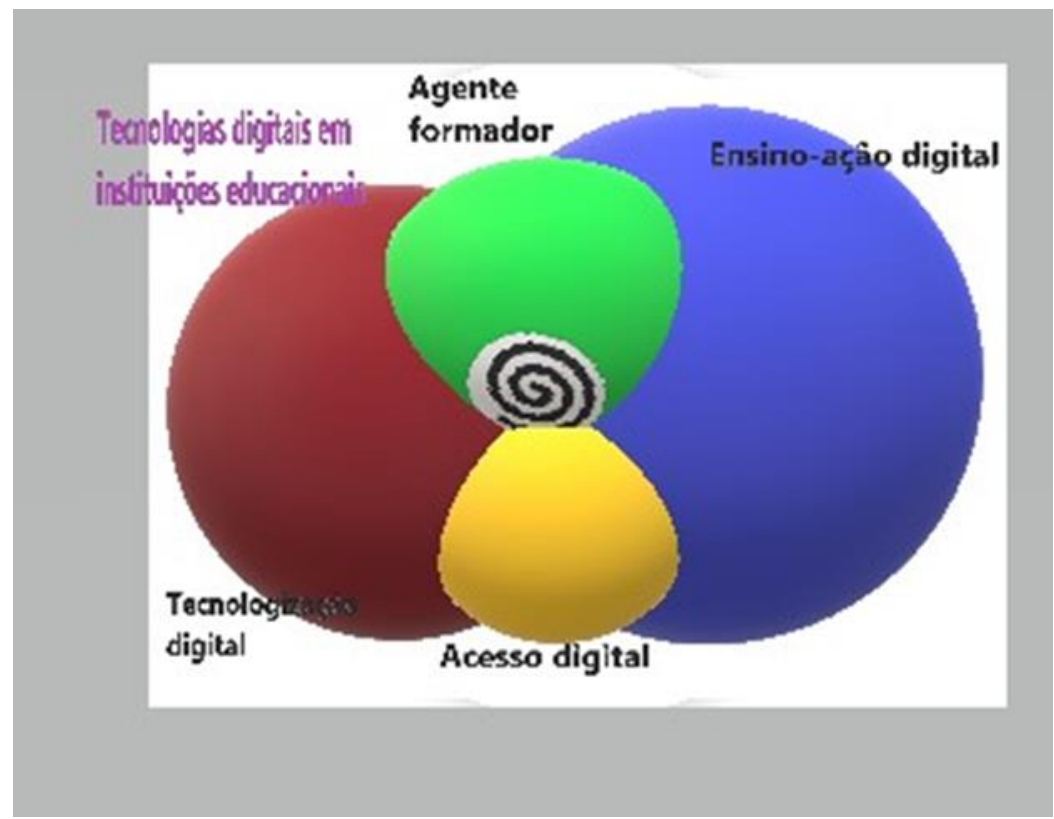

Fonte: Viegas (2018)

As tecnologias digitais dentro das instituições de ensino fazem um movimento espiral que perpassa em algum momento alguma dessas subcategorias que formam o letramento digital e que, em alguns momentos, podem até ocorrer concomitantemente.

Assim, a escolha dessa categoria para análise justifica-se para apresentar quais têm sido os referenciais teóricos mais usados, tanto na formação de professores, quanto no letramento digital, e identificar qual é a tendência dos pesquisadores. Os autores apresentados representam principalmente estudos voltados para a dimensão cultural dos letramentos, por levarem em consideração nos seus estudos os aspectos do contexto social do grupo estudado.

A partir das subcategorias e suas propriedades e dimensões podem ser analisados grupos específicos para dar continuidade ao estudo do letramento digital na formação docente, são eles:

A. Tecnologização Digital: refere-se aos trabalhos que priorizam a temática da inovação e apropriação tecnológica; das potencialidades dos recursos digitais; a reflexão e uso criativo de tecnologias digitais; da complexidade e multiplicidade do letramento digital; do uso de tecnologias digitais de forma instrumentalizada; da leitura e escrita com suportes digitais; do analfabetismo digital e letramento digital funcional; da resistência e falta de consciência do universo digital no ensino.

B. Agente Formador: diz respeito aos estudos sobre a competência reduzida e o baixo conhecimento das tecnologias digitais; as crenças dos professores sobre o uso dessas tecnologias; a comodidade que impede a inserção de recursos digitais em sala de aula; 
minimizando a resistência dos professores; a necessidade de formação inicial e continuada sobre tecnologias digitais; relação pessoal e profissional do uso da tecnologias digitais; retratação e reflexão do processo de formação docente; desenvolvendo macrocompetências e supracompetências de letramento digital. Observando analiticamente essa subcategoria, podese descrever que compreendida como um instrumento, na sua espacialidade, na forma de operacionalização de ações viabilizando práticas de letramentos.

Considerando os letramentos como formas de ação e interação das tecnologias digitais, alcançam o grupo que utilizam tecnologia e linguagem. Configuram-se pelos processos de comunicação, seja pela leitura, pela escrita e com o uso de instrumentos digitais e que são articulados para resolução de atividades cotidianas. Como instrumento, podem ser conceituadas de ferramentas abstratas e concretas para se atingir o objetivo proposto, que tem sido utilizado na educação e na formação de professores.

Essas propriedades definem o fenômeno da tecnologização digital pela apropriação e uso de recursos digitais, de forma efetiva, mas pouco ou quase nunca se menciona ainda as perspectivas dos letramentos crítico e cultural. E, por isso, que ocasiona ainda dentro dessa subcategoria os aspectos tidos como negativos, que são o analfabetismo digital, o letramento digital funcional e a resistência dos professores.

C. Ensino-ação Digital: trabalhos que priorizam o pesquisar falhas e lacunas das tecnologias; a subutilização do potencial educacional das tecnologias digitais; as políticas públicas de investimento escolar na formação sobre tecnologias digitais; a potencialização da aprendizagem com ferramentas digitais de maneira integrada; as práticas pedagógicas, a educação a distância e as interações e as colaborações no meio virtual; os documentos escolares.

As tecnologias acabam sendo inseridas nas práticas de ensino, inicialmente ingressaram na forma da escrita, dos livros didáticos, dos materiais impressos. Hoje, as tecnologias são as digitais, que ingressam com menos controle do que os outros recursos ingressaram. Isto está diretamente relacionado à massificação do ensino e às políticas que garantem a educação a todos, a defasagem na formação de professores dentro dessa área e o fácil acesso às ferramentas digitais. Mas esses são processos externos.

Dentro do ensino-ação digital verifica-se, além da necessidade de reorganização de currículos, uma mudança nas práticas educativas, já que a educação vertical e a aprendizagem colaborativa não podem ser mutuamente aplicadas. Enquanto na educação vertical existe a figura de um detentor do conhecimento e os sujeitos da aprendizagem apenas recebem essas informações, na aprendizagem colaborativa existe uma nova configuração desse processo, ou 
seja, não existe apenas um detentor do conhecimento, o professor, o aluno, o tutor... estão em constates trocas, conforme seus interesses e conhecimentos. Nesses casos, há interações e elas também podem ser virtuais, possibilitando a colaboração com pessoas conhecidas e desconhecidas, em qualquer parte do mundo que tenha acesso à rede.

D. Acesso Digital: estudos que se direcionam à inclusão social e digital; à inserção de tecnologias digitais nas universidades e na escola; à falta de acessibilidade contínua.

A escola como representação de um grupo social também apresenta a inclusão/exclusão social e, consequentemente, o mesmo fenômeno se repete ao tratar das tecnologias digitais dentro do ambiente escolar.

Apesar da massificação e o acesso aos diferentes aparelhos móveis ter aumentado significativamente, o Brasil e o estado de Minas Gerais têm uma extensão significativa que traz locais com tecnologia de ponta e outros lugares sem esse mesmo privilégio. Existem inúmeras estratégias e ações do governo para tentar diminuir essas desigualdades. Vale ressaltar que elas começam ainda na formação docente.

Essa subcategoria de acesso digital traz consigo as seguintes propriedades e dimensões: a. inclusão social e digital; b. inserção de tecnologias digitais nas universidades e na escola; c. falta de acessibilidade contínua.

Assim, conceitua-se como a possibilidade de diferentes grupos, seja de professores, seja de alunos, terem acesso às tecnologias digitais na educação formal. E para que isso aconteça as políticas públicas tem que atender a demanda da diversidade e fazer com que esse acesso seja contínuo.

\section{Considerações finais}

As práticas sociais de leitura e escrita, na atualidade, não conseguem mais ser dissociadas das tecnologias digitais de informação e comunicação. Assim, para uma compreensão conceitual de letramento digital, se faz necessário uma apreensão do movimento dos novos letramentos nas relações sociais, estabelecer a indissociabilidade entre a oralidade e a escrita, e contextualizar ao ambiente escolar, percebendo as exigências de habilidades e conhecimentos tecnológicas, não só dos estudantes, mas também do professor.

Como resultado ao objetivo de abordar o estudo a respeito do conceito de letramento perpassando por uma reflexão das ações influenciadas pelas tecnologias digitais nas práticas de ler e de escrever no contexto educacional, percebemos que, apesar de o público de estudantes ter convívio com as mídias digitais, algumas práticas de letramento são mantidas, 
outras, pela dinamicidade, são efêmeras, por isso as relações entre o conhecimento e a tecnologia na formação docente devem permitir a autonomia e criticidade nas práticas sociais. Para tanto, os professores e os estudantes precisam aprimorar habilidades e competências que perpassam pelas dimensões operacional, cultural e crítica de uma sociedade em rede.

Diferentes práticas podem ser consideradas como letramento digital, destaca-se, neste estudo, que apenas a operacionalização não é suficiente para ser considerado letrado, se não se remeter, também, ao modelo autônomo de letramento. Para ser configurado como letrado digital, o sujeito deve ter consciência do conteúdo e da operacionalização, de modo que possa transformar sua prática, caso seja necessário.

As tendências da produção acadêmica nessa região demonstraram que o letramento digital do professor, integrando professores atuantes e não atuantes, ainda é incipiente e significativo apenas para pequenos grupos, não atendem o todo do referido estado, porque são práticas realizadas, principalmente, em escolas que, geralmente, estão próximas do polo de Instituições de Ensino Superior que oferecem cursos de pós-graduação ou em escolas que possuem atividades ou projetos de extensão com um professor pesquisador.

Após a análise dos resumos e dos temas das teses e dissertações das pesquisas realizadas no estado de Minas Gerais, ao serem combinadas, as subcategorias formam a categoria emergente que dá uma conceituação ao letramento digital na formação de professores. O letramento digital como categoria central pode ser definido como o "ensinoação na tecnologização digital do agente formador e o acesso digital escolar".

Entende-se como a possibilidade e a potencialidade que futuros professores e professores atuantes têm para se tornarem habilitados a exercer a magistratura com auxílio de recursos digitais dependem do processo de apropriação e de dedicação desse grupo, pois o seu mau uso pode ocasionar uma subtilização das tecnologias digitais. Apesar da resistência dos professores, algumas atividades que vem sendo aplicadas em alguns grupos têm demonstrado resultados, quando essas práticas se relacionam com as atividades cotidianas da comunidade escolar e podem ser reproduzidas.

\section{REFERÊNCIAS}

AZEVEDO, D. S. et al. Letramento digital: uma reflexão sobre o mito dos "nativos digitais". Revista Renote: Novas Tecnologias em Educação. Porto Alegre, v. 16, n. 2, p. 1-11, jul./dez. 2018. Disponível em: https://seer.ufrgs.br/renote/issue/view/3640/showToc. Acesso em: 20 jan. 2019. 
BARTON, D.; HAMILTON, M. Local literacies: reading and writing in one community. Revised ed. London: Routledge, 2012.

CASTELLS, M. A sociedade em rede: do conhecimento à acção política. Traduação Tânia Soares. Rio de Janeiro: Casa da Moeda, 2005.

DUDENEY, G.; HOCKLY, N.; PEGRUM, M. Letramentos digitais. 1. ed. São Paulo: Parábola Editorial, 2016.

FREIRE, P. Pedagogia da autonomia: saberes necessários à prática educativa. 51. ed. Rio de Janeiro: Paz e Terra, 2015.

GLASER, B. G.; STRAUSS, A. L. The discovery of grounded theory: strategies for qualitative research. 1. ed. [s.l.] Routledge, 1999.

KLEIMAN, A. B. Modelos de letramento e as práticas de alfabetização na escola. In: KLEIMAN, A. B. Os significados do letramento: uma nova perspectiva sobre a prática social da escrita. São Paulo: Mercado de Letras, 2014.

LÉVY, P. Cibercultura. São Paulo: 34, 1999.

MATENCIO, M. DE L. M. Analfabetismo na mídia: conceitos e imagens sobre o letramento. KLEIMAN, A. B. In: Os significados do letramento: uma nova perspectiva sobre a prática social da escrita. Campinas: Mercado de Letras, 2014.

OLSON, D. A escrita como atividade metalinguística. In: OLSON, D. Cultura escrita e oralidade. São Paulo: Ática, 1995. p. 267-286.

PALFREY, J.; GASSER, U. Nascidos na era digital. Porto Alegre: Grupo A, 2011.

PORTO, T. M. E. As tecnologias de comunicação e informação na escola: relações possíveis... relações construídas. Revista Brasileira de Educação, Rio de Janiero, v. 11, n. 31, p. 43-57, 2006.

PRENSKY, M. Digital Natives, Digital Immigrants. On the horizont, v. 9, n. 5, out. 2001.

ROJO, R. Escol@ conectada: os multiletramentos e as TICs. São Paulo: Parábola Editorial, 2003.

ROJO, R. Pedagogia dos multiletramentos: diversidade cultural e de linguagens na escola. In: ROJO, R. Multiletramentos na escola. São Paulo: Parábola Editorial, 2012. p. 264.

SCRIBNER, S.; MICHAEL COLE. The psychology of literacy. Cambrigde: Harvard University Press, 1981.

SILVA, S. L. da. Letramento digital de professores em contexto de formação continuada. Orientador: Isabel Cristina Alves da Silva Frade. 2004. Dissertação (Mestrado em Educação) - Programa de Pós Graduação em Educação da Faculdade de Educação, Universidade Federal de Minas Gerais, Belo Horizonte, 2004. Disponível em:

https://repositorio.ufmg.br/handle/1843/IOMS-67MMSR. Acesso em: 13 fev. 2020. 
SNYDER, I. Literacy and technology studies: past, present, future. ACER Research Conference. Oct. 1999.

SOARES, M. Letramento em verbete: O que é letramento? Revista Presença Pedagógica. Belo Horizonte, v. 2, p. 15-25, 1996.

SOARES, M. Novas práticas de leitura e escrita: letramento na cibercultura. Educação \& Sociedade. Campinas, v. 23, n. 81, p. 143-160, 2002.

SOARES, M. Letramento: um tema em três gêneros. Belo Horizonte: Autêntica Editora, 2014.

STRAUSS, A.; CORBIN, J. Pesquisa qualitativa: técnicas e procedimentos para o desenvolvimento de teoria fundamentada. Porto Alegre: Penso, 2008.

STREET, B. V. Letramentos sociais: abordagens críticas do letramento no desenvolvimento, na etnografia e na educação. São Paulo: Parábola Editorial, 2014.

TARDIF, M. Saberes docentes e formação profissional. Petrópolis: Vozes, 2014.

VIEGAS, P. P. C. Letramento digital docente em Minas Gerais: um estado do conhecimento. Orientadora: Ilsa do Carmo Vieira Goulart. 2018. Dissertação (Mestrado Profissional em Educação) - Programa de Pós-Graduação em Educação, Universidade Federal de Lavras, Lavras - MG, 2018. Disponível em: http://repositorio.ufla.br/jspui/handle/1/29554. Acesso em: 13 fev. 2020.

\section{Como referenciar este artigo}

VIEGAS; Patrícia Peixoto Carneiro; GOULART, Ilsa do Carmo Vieira. O estado da arte da produção acadêmica sobre o letramento digital na formação docente. Revista IberoAmericana de Estudos em Educação, Araraquara, v. 15, n. 1, p. 125-145, jan./mar. 2020. eISSN: 1982-5587. DOI: https://doi.org/10.21723/riaee.v15i1.12217

Submetido em: 03/02/2019

Revisões requeridas: 10/05/2019

Aprovado em: 01/06/2019

Publicado em: 02/01/2020 